\title{
Women's perspectives on quality of maternal health care services in Malawi
}

This article was published in the following Dove Press journal:

International Journal of Women's Health

\section{Kennedy Machiral,2 \\ Martin Palamuleni ${ }^{2}$ \\ 'Department of Agriculture \\ Economics, Lilongwe University of Agriculture and Natural Resources, Lilongwe, Malawi; ${ }^{2}$ Population and Research Unit, North West University, Mmabatho, Republic of South Africa}

\begin{abstract}
Despite promotion by many stakeholders to improve maternal health outcome in many developing countries including Malawi, many analysts agree that the utmost success in maternal health will arise if maternal health care services are an unparallel led source for women's health care solutions for any problem related to childbirth. Health advocates worldwide claim that even though maternal services are provided, women's utilization of such services has not been ascertained. The objective of this study was to explore women's perspectives on the quality of health care service delivery in Malawi. This article therefore investigates women's perspectives on the quality of maternal health care services in Malawi. We used six focus group discussions in six health facilities that were selected across Malawi. We found that erratic availability of medical resources and unethical practices among health workers adversely affected quality of maternal health care service delivery. We concluded that the expensive routine operational audits of medical resources and service delivery across health facilities are imperative if women's health outcomes are to be enhanced in Malawi.
\end{abstract}

Keywords: public health, health care, quality of care, access, Malawi, women's health

\section{Introduction}

In most developing countries including Malawi, maternal mortality remains a major public health challenge despite decades long pledges and declarations aimed at improving quality of maternal health care delivery and subsequent reduction of the worst maternal health outcomes. ${ }^{1-3}$ For example, neighboring countries such as Mozambique, Zambia and Tanzania are reported to be on track in women's use of maternal health care services and have achieved maternal mortality reduction by $4.2 \%, 3.8 \%$ and $3.7 \%$, respectively, on a yearly basis during the period 1990-2015. ${ }^{3}$ It has come to light that Malawi, alongside Lesotho, in the same region, is lagging behind in women's use of maternal health care services, which results in the two countries still experiencing persistent low yearly maternal mortality reduction of $1.6 \%$ and $1.0 \%$, respectively, over the same period. ${ }^{3}$

Malawi is a country that is situated in the southern part of Sub-Saharan Africa with an estimated population of $17,473,734$ in the year $2016 .{ }^{4}$ Of this population, $\sim 49.9 \%$ are females, and $>90 \%$ of the population are residents of rural areas in the country. ${ }^{5}$ Economically, the country's gross domestic product (GDP) experienced a reduction in the growth rate from $9.5 \%$ in 2010 to $5.8 \%$ in $2015 .{ }^{6}$ Owing to this economic decline, a number of the sectors operate under a constrained budgetary support, which consequently affects the quality of public service delivery. Of these sectors, the health sector is the most notably and heavily affected sector that experiences inadequate health care personnel, medical resources, equipment and supplies, 
a situation that aggravates not only substandard quality of care but also undesirable low health outcomes more especially among the vulnerable women in Malawi compared to their counterparts in the neighboring countries. ${ }^{6,7}$ Yet over time, Malawi has been training skilled health workers to meet the shortage of the health personnel in the country. ${ }^{7}$ However, this effort proves to be futile due to the country's economic situation that affects investment in health care services. ${ }^{7}$ This situation aggravates a continued migration of the health workers either to nonpracticing health care jobs, to other countries within the region or to countries overseas in pursuit of greener pastures. ${ }^{7}$ This continued shortage of the health care personnel not only causes an imbalance in health practitioner-patient ratio but also impairs maternal service delivery meant to meet women's emergent health needs. ${ }^{8}$

Despite these challenges, the country has made a lot of pledges in international declarations and conventions that are aimed at improving the quality of primary health care services and reducing maternal public health challenges. ${ }^{1-3}$ It is worthy to note that in spite of this development, the country's maternal health outcome remains a challenge compared to its neighboring countries. Women still experience utilization challenges on maternal health care services during pregnancy, childbirth and postnatal care. ${ }^{7,8}$ For instance, the 2010 Malawi Demographic and Health Survey (MDHS) report indicates that of the 23,020 women aged between 15 and 49 years who participated in the survey, only $46 \%$ had at least four antenatal care (ANC) visits during pregnancy, $57.3 \%$ of which were reported to have delivered in public health care facilities, and only $43 \%$ had had a postnatal checkup within 48 hours after delivery. ${ }^{9}$ This means that the low women utilization level of maternal health care services increases women's vulnerability of experiencing the worst health outcome.

This experienced capacity deficiency within the health care facilities directly or indirectly influences women's use of maternal health care services in the country. As such, there is need to explore women's perspectives on the quality of health care service delivery in Malawi. This is important in providing an understanding of the quality of health care operations and subsequent improvement in maternal health care service delivery in the country. ${ }^{8}$

The quality of maternal health care is a profound factor that impacts on the delivery of continuum of care among women in most of the sub-Sahara African countries. This is attributed to existence inequalities within and between the developing countries in the way operation management of health care services is implemented. This situation subsequently affects the quality of care, and it increases the women's use of alternative health care services as opposed to the conventional public-supported health care facilities. ${ }^{10}$ In Malawi, despite the efforts made to promote quality of care to meet the emergent maternal needs such as availability of health personnel to attend to women health issues at each facility, infrastructure developments to meet basic maternal health care, provide overtime pay to health care personnel for extra hours worked, among others, ${ }^{5,8}$ women's perspectives with regard to quality of care across the three regions of the country require continued exploration. This is because such identified information can be significant in suggesting robust and long-term maternal health care interventions befitting different women at the national level and providing a learning curve to other developing countries in as far as quality of maternal health care service delivery is concerned. This study can be replicated in some of the Sub-Sahara African countries that are experiencing similar low utilization levels of maternal health to improve on maternal health outcome based on the findings from this study. Therefore, the question that begs for an answer is: What are the perspectives of women with regard to the quality of maternal health care service delivery in Malawi?

\section{Materials and methods Study area}

The study was carried out in three administrative districts, namely, Mzimba in the Northern Region, Ntcheu in the Central Region and Chiradzulu in the Southern Region. These districts were conveniently selected on the basis of their reported increase in women's access to safe motherhood information. This access to safe motherhood information stood at 64\% in Mzimba, 71.2\% in Ntcheu and 65\% in Chiradzulu. ${ }^{9}$ Additionally, the districts were reported to have not only hospitals that are providing comprehensive emergency and obstetric care services but also some health centers that coordinate and support basic emergency and obstetric care service. ${ }^{8}$ Among the purposefully selected health centers are Manyamula Health Centre in Mzimba, Tsangano Health Centre in Ntcheu and Namitambo Health Centre in Chiradzulu. As such, the study conveniently selected these district hospitals and correspondent health centers to investigate the perspectives of women on maternal health care service delivery in Malawi.

According to Malawi Health Sector Strategic Plan 2011-2016, $76 \%$ of the population in Mzimba, 92\% in Ntcheu and $98 \%$ in Chiradzulu District reside within the radius of $8 \mathrm{~km}$ to the health care facilities. ${ }^{8}$ Furthermore, 
the 2010 MDHS Report pointed out that $\sim 51 \%$ of the women aged between 15 and 49 years had four or higher ANC visits in Mzimba, 51.3\% had in Ntcheu and 40.7\% had in Chiradzulu. Regarding mainstream health care childbirth, $\sim 36.7 \%$ of women in Mzimba, 35\% in Ntcheu and $39.0 \%$ in Chiradzulu delivered in public health care facilities, but $46.5 \%, 47.5 \%$ and $48.8 \%$ of them did not come for postnatal care services. ${ }^{9}$

\section{Study population and analytical approach}

The study used qualitative approach to answer the research question. There were six focus group discussions (FGDs), and each had a minimum of six women participants to a maximum of 12 . We interviewed a total of 58 women across the country. To ensure homogeneity of the participants in each FGD, we requested a senior manager at each health facility to assist in purposefully identifying women who were at the facility seeking maternal health care services.

Women who were identified and selected were asked for their consent to participate in the FGD sessions at every health facility visited. To be guided during the course of the FGD sessions, the researchers used a discussion guide list to direct the flow and scope of the discussion during each session. The content of the FGD comprised quality of maternal delivery issues that were targeting capture of women's perspectives from the following subtopics: 1) institutional and other barriers affecting their decision to use maternal health care services; 2) explain on the quality of maternal health care services delivery by the health facilities and 3) provide an account of the nature of anticipated maternal health care services from such public health care facilities to improve their maternal health outcome.

Thereafter, when each FGD was conducted, each discussion was recorded with an audio voice recorder and later transcribed verbatim and translated into the English language. Two translators were engaged to verify the transcripts for authenticity and quality assessment of the manuscripts. The manuscripts were imported into ATLAS-ti 7.0 where codes were generated to aid an analysis process. A thematic framework was developed in Microsoft word. These generated themes were compared with the original manuscripts so as to understand the differences and similarities of the women's perceptions with regard to quality of maternal health care service delivery. Furthermore, an axial coding was involved in which the researcher reconceptualized the fundamental code along with the text. Narrative text was used on the developed themes in which quotations were used to illustrate the text and inform the meaning to the reader. This was done to ascertain validation of quotes.

\section{Ethical approval}

All women who were approached and asked to participate in the study accepted. Ethical approval was obtained from the ethics review board of North West University, which accorded an ethical number NWU-00394-15-A9, and the district health offices in Malawi. As indicated earlier, we obtained informed consent to participate in the FGD from the participants before the commencement of each session. In addition to this, the principle investigator asked the participants that permission to be recorded using an audio recorder before each session, and were also told to be comfortable to ask any question, provide comments and seek clarity on any issue being discussed. At the same time, at each session, consent to use an audio recorder to capture the proceedings of the discussions was sought by the principle investigator before each facilitated FGD session. Each collected datum was saved using authentication credentials for data confidentiality.

\section{Limitations of the study}

Given that the interviews were conducted at the health facility where the participants received maternal health services, this might have influenced their responses. Some women expressed fear as they purported that the interviewers were government officials and were not free to express themselves thoroughly at the commencement of the exercise but picked up later in the exercise. In some instances, the interviewers were men and some women were expressing little shyness to explain women issues to men. This might have limited and affected on the quality of data that were captured. In addition, as women who were escorted by their spouses/partners reported the facilities being time effective and efficient, it would have been better to include men to have a holistic perspective of the quality of services from the men dimension, which was limited based on this study.

\section{Results}

From the qualitative analysis of data, four major themes were evidently derived. These were perceived nature of support that women got upon arrival at the health facilities; perceived quality of care, in general, at prenatal, intranatal and postnatal care services across the facilities; perceived barriers that prevent women from seeking immediate maternal health care services and suggestions made aiming at improving delivery of maternal health services in Malawi. 
Perception of support received upon arrival at the prenatal health care facilities

In as far as perception of support received upon women's arrival at the health care facilities for different services, namely, prenatal, intranatal and postnatal care was concerned, the study found out that the hospital and health care facilities had different ways of receiving women to the health facilities for these services. On the one hand, the majority of the participants indicated that reception to prenatal care services is better supported and easily accessed. In addition, it was also mentioned that in as far as ANC services are concerned, preliminary information on birth preparedness, family planning and significance of breast impressed majority of the women. The following are some of the points indicated:

When I came for the ANC services, I was very much impressed by the health workers' conduct during the training sessions on important topics of reproductive health such as birth preparedness, importance of HIV test during pregnancy, breast feeding and how to make self-assessment and identify any pregnancy related complications and seek health care interventions immediately. [FGD 6, Health Facility, Southern Region]

I do not have problems with the reproductive health educative programs received during my ANC visits. The sessions held are clear even though time was not enough to ask questions. [FGD 2, Health Facility, Northern Region]

I am very impressed by the ANC education that we receive here. As you saw what is happening inside [examination room]. The nurses were very busy, diligently doing vital services like pulse, breathing rate, temperature reading, measuring blood pleasure, measuring weight and height and carrying out some urine tests as well as making malaria diagnosis. [FGD 8, Health Facility, Central Region]

On the other hand, some of the women raised concerns that despite coming earlier to the health facility seeking maternal health services, the level of attention acquired from the medical personnel was not adequate. On the same note, some women indicated lack of pregnancy conception knowledge due to their reliance on contraceptives as the reason for delay, whereas others indicated that their delays are partly due to cultural influence. It is imperative to note that some women culturally believed that pregnancy must not be disclosed to the people in the first months to avoid being bewitched. This consequently resulted in delay in the utilization of health care services by women, which, on average, majority of them started using ANC services
6 months after conception. The following is what some of the women reported during the FGD sessions:

When I got pregnant, I was not aware. When my menstruation stopped, I thought it was normal. This is because my periods have been irregular due to contraceptives. I had fever and decided to go to the health center where the clinical officer tested for malaria and pregnancy as well. The result turned out that I was pregnant. [FGD 7, Hospital, Central Region].

I knew I was pregnant. I deliberately delayed visit for ANC services. This is because I wanted the pregnancy to develop and advance. It is my belief that some people in my village can bewitch me to either experience complications during my pregnancy or suffer a miscarriage or have other challenges that might affect my normal delivery. [FGD 7, Hospital, Southern Region]

If you fall pregnant, it remains a secret and you don't tell anyone until the pregnancy is advanced in months. I don't just share such experience with anyone because you never know who is capable of harming you. This often results in the delays to seek prenatal care services, within the first months of the pregnancy. [FGD 2, Health Center, Northern Region]

Another aspect that emerged during the FGD was that women who indicated to come to the health facility with their spouses or partners to seek ANC services found the services to be time effective and efficient. However, the majority of the participants lamented that their spouses/partners never saw the need as situation was claimed as a pregnancy-related issue and hospital/health care visits as women issues. Some women had this to say:

When I asked my husband to escort me to the hospital, he did not respond and on the day that I had an appointment he left the house early without either communicating or updating me of his programs.

Another woman said:

Some men are afraid of escorting their wives for any maternal health care services because they don't want to be subjected to HIV/AIDS tests as the government advocates that every couple should know their HIV/AIDS status at the time they are expecting a child in order to improve both maternal and childbirth outcome. [FGD 7, Hospital, Southern Region]

An interesting revelation from women reiterated that those women who are always escorted by their spouses to the 
health care facility seeking antenatal services had had better services rendered to the couples. This is because the health personnel were giving them preferential treatment as a way of motivating them to seek maternal health as a family. The following is what one woman commented:

When I was escorted by my spouse to receive prenatal care services, I got preferential treatment compared to my colleagues who come on their own or with their female relatives. [FGD 3, Hospital, Central Region]

\section{Challenges experienced during the prenatal care service}

The study found out that despite the majority of women who reported being satisfied with the quality of prenatal care services acquired, some women reported the existence of little challenges associated with prenatal care service delivery in some health care facilities in the country. For instance, some health facilities operated without medical equipment such as scanning devices and that affected quality of care delivery among women in need of such scanning services during ANC utilization. The following are the concerns some of the women raised:

This district hospital has no functional ultrasound scan and we were told that we will be taken to the tertiary health care facilities for ultrasound scanning but we are now being told that there is no fuel for the ambulances that are to ferry us to the tertiary hospital which is over $110 \mathrm{~km}$ away from here.

I came here seeking for scan services so that I know the position of the baby. The health personnel on call just told me that the ultrasound scan is not working. In trying to assist me, he referred me to a private practitioner, who operates an ultrasound scan at a cost. You see, because I am in dire need of a scan due to what I am feeling. I have no option but to pay for this private scan services. Yet, another woman whom I met in a queue lamented that she had no money and opted to return to her village without accessing this private for profit medical services due to lack of money. This incapacitates most women in seeking other important subsequent maternal health care services in the health facility and opted for alternative somewhere. [FGD 1, Hospital, Northern Region]

During the FGD, the general view of the participants was that distance to the health care facilities, transport to the health facilities and direct or indirect costs associated with the drug access were the major factors negatively impacting on women's use of prenatal care services in the country. Some women's views on these challenges were as follows:

I do not stay very far from the health center. But the state of being pregnant makes me take time to reach the health center. I always think twice whenever I think of coming to the health center more importantly at the time when the pregnancy is in its advanced state, the distance is the source of concern.

There are no ambulatory services due to inadequate or no fuel to manage the transport services within the health systems which hinders access to referral hospital. You come here and you are told that the health center does not have medical resources such as drugs. [FGD 8, Health Facility, and Southern Region]

\section{Perceived quality of delivered intrapartum and postpartum care services}

Perceived quality of intrapartum service delivery during childbirth includes the care that the women get upon arrival at the health facility for childbirth, any medical attention and tests acquired from the skilled health personnel and any care given to them during and immediately after childbirth. We found out that women were of the view that the quality of care acquired from the health care personnel during childbirth period was much lower compared to the care that was administered to them during prenatal care services. Most women complained that there were a lot of delays from the health workers to respond to their needs if any need arose. Additionally, some participants reported that some health workers gave them attitudes and in some instances they used vulgar languages in times when the woman required some attention during the intrapartum admission. This is what some women had to lament:

The quality of care in this intrapartum facility is totally different. I am not satisfied with the quality of care being rendered to us compared to prepartum care services. It is as though during prenatal period, they were rendered trying to entice us to come for further maternal health care services, but my experience is very bad and I cannot recommend anyone to come for childbirth here. [FGD 8, Health Centre, Southern Region]

There is shortage of beds to accommodate all expectant women. This is a great concern. As a result, we are told to go and sleep in the kitchen with our guardians.[...] Despite all these challenges, I am not worried. My main interest is that I am close to the skilled birth attendants so that when situation gets bad I am attended to by them. ... 
We are not adequately fed in this health facility. The doctor tells us that there is no adequate food here as such. We are given one meal per day. So there is no difference with staying and waiting at home because my guardian has to prepare and give me food all the time. Imagine! The food stuffs that the guardian prepares are obtained from home. Sometimes you delay to come if you do not have food to eat while waiting for delivery, then you do not come. ... You can imagine, with the little that I brought from home, I am even sharing it with some women who have no food at all. They were anticipating that they will be given food from the health care facility, which is not the case. [FGD 2, Health Centre, Northern Region]

There are bed shortages in this health center. I gave birth last night and you will be shocked to hear that I am sharing a bed with another woman who gave birth today. A nurse told me to share the bed because the other woman did not have a bed. Such sleeping arrangements are very scary as they can result in injury of the newly born babies. But what can we do? I am hoping that the clinical officer will discharge me today. Besides, it is unhygienic and unsafe for the two newly born babies and their mothers to share a single bed. There is high probability that either you as mothers or the newly born babies may contract some diseases. The situation is quite unbearable but what can we do? Last week we were shifted from the female ward to the kitchen where we slept with our guardians just to create space for women who had given birth. This health center is highly congested. [FGD 8, Health Center, Southern Region]

\section{Barriers preventing women's immediate decision to seek maternal health care services}

Most participants echoed three main barriers preventing them from seeking maternal health care services in Malawi. First, the issue of distance to the health center was the most common among women attending prenatal, postnatal and preventing skilled birth attendants. Second, the majority of women indicated that health workers' attitude change to the worst compared to the type of assistance they got at the prenatal care facility and the time they were admitted for childbirth. Most women indicated that the health care providers are very unfriendly and do not take good care of them to cater for their physiological change that comes as a result of the pregnancy:

The nurses are very unfriendly and uncooperative. That is why we prefer home delivery to health care facility delivery because at home, your assistant gives you full attention and responds to your requests. That does not happen in the health center because once you call a nurse, she shouts at you. What they forget is that they are recruited by the government to assist us [patients]. Why do they behave like that? It is better to deliver at home then. [FGD 8, Health Centre, Southern Region]

The third barrier associated with maternal health care services in the country is the high levels of congestions within the health care facilities. This results in service delivery delays despite women's timely effort to access the health care facility in view of their health condition.

After being delayed in that manner you are later told that the health care facility is short of resources and require either to be referred to the tertiary hospital for some specialized care which oftentimes becomes futile due to erratic availability of fuel or lack of medicine within the health care facility due to lack of drugs at the drug repository center. [FGD 2, Hospital, Northern Region]

According to Malawi Health Sector Strategic Report 2011-2016, the country's health system has been experiencing cash flow problems to support supply chain logistics and procurements of medical equipment and supplies and drugs to the health centers. The situation has become so desperate that some women pointed out their disappointments with regard to the challenges within the health facilities and its dire consequence on quality of care delivery:

The issue of fuel and shortage of essential drugs within the health care facilities is more apparent now. It's a national problem. Therefore, although the extensive campaigns are made to promote women's use of health care facilities, the shortage of essential resources within the maternal health care facilities really prevents us from depending on modern health care facilities as they cannot fully provide what is needed to support our maternal health care. [FGD 4, Hospital, Central Region]

\section{Discussion}

In this study, the perspectives of women in Malawi with regard to maternal health care service delivery still indicated to have different challenges in terms of access, quality of maternal health care delivery, in itself, have remained a significant barrier affecting immediate use of prenatal, intranatal and postnatal care services, despite the country's recognition of the need to improve the quality of maternal health care services for better maternal health outcome. Malawi 
made this commitment at the International Conference on Population and Development in 1994, Cairo, Egypt, and the Fourth World Women Conference in 1995, Beijing, China. The study found that perspectives of women with regard to prenatal health care services delivery were taking an improvement trend relative to quality of intrapartum and postpartum care in the country. On the same, it was earlier postulated that better maternal health outcomes have been linked to not only women's full participation and use of prenatal care services but also other maternal health care supports during the gestation period. ${ }^{11,12}$ In the current study, it was noted that most women experienced challenges as they were not respected at the facilities. For instance, some women reported that they were being yelled by the health care personnel due to their maternal health state; this implies that the health workers lacked respect and human decency meant to promote quality of service delivery and maternal health well-being. With these variations in as far as perceptions of women regarding delivery of maternal health care services in Malawi are concerned, they require immediate pro-women-based interventions if the current women's perceptions on the quality of maternal health care service delivery are to improve.

Our key results indicate that the Malawi's prenatal health care services are better and above average compared to both administered intrapartum and postpartum care service deliveries. In the literature, it was found that extensive engagement of women at the time they are using prenatal care services motivates them to use intrapartum and postpartum care services within the health care facility in India, Tanzania and Zimbabwe. ${ }^{13-15}$ Our study shows that as much as women were found to be more interested in patronizing prenatal care services, their interest in the use of further maternal health care services such as intrapartum and postpartum care decreases. An earlier study indicates that such challenges are partly due to unsatisfactory services that the women get at the time they are receiving prenatal care services ${ }^{16}$ and partly due to unavailability of some medical services that negatively affect women's decisions on future utilization. ${ }^{17}$

The study also found that prenatal care services in Malawi have necessary routine checks as defined by focused ANC strategy where women upon arrival to acquire prenatal care services have routine vital tests such as blood, blood pressure and urine tests; birth preparedness education from the health care facility facilitator and other vital diagnosis like malaria in addition to advocacy programs to encourage institutional childbirth over home-based childbirth. Despite these positive developments, the majority of the women indicated to have low willingness to deliver at the health care facilities due to operational challenges such as distance to the health care facility, which is aggravated by pregnancy and lack of availability of transport either from supply side of health or due to demand side. Challenges such as lack of spousal support, lack of transport money to access the health care facility and inadequate knowledge and experience to understand their pregnancy complications were defined as factors causing delay or factors that promoted noninstitutional childbirth in Malawi. Previous studies attributed such supply side challenges of maternal health care service delivery to factors such as inadequate and delayed health care financing, which contribute not only, in the long term, positively to suboptimal performance of health care facilities in developing countries ${ }^{18}$ but also to subsequent low-quality of care delivery due to inadequate staff levels to meet the needs of clientele; erratic availability of medical resources, supplies and equipment $t^{7,13}$ and inadequate availability of requisite drugs to meet maternal health demands. ${ }^{19}$ Such supply side challenges affect seamless operation of pro-transport-based health care services such as intrapartum care services in Malawi.

From the demand side of health care services, the present study found that some women in Malawi delayed their first ANC visit. On the one hand, this is due to limited knowledge of their reproductive lifecycle. The study found that women delay seeking ANC services due to their cultural belief that revealing one's pregnant state may attract bad luck for them. Inadequate knowledge of their reproductive lifecycle oftentimes results in women realizing that they are pregnant in the third or fourth month. The cultural beliefs about pregnancy are myths that end up discouraging women from seeking early maternal health care. ${ }^{14,19}$ Pro-women community-based interventions help change women's perspectives, and this result in increased use of maternal health care services against deep-rooted cultural barriers. ${ }^{15,20}$

The participants underlined a number of issues on quality of service delivery that can help improve their willingness to utilize maternal health care service for every maternal health demands. Participants in the prenatal care service utilization group indicated that the quality of prenatal care service received was very good. Some of the women in this group could not give the details of what they perceived to be benefits of utilizing the prenatal care services. They could not precisely outline how significant was the maternal health care services delivery. These are normal checks they expect during pregnancy, even if they have delayed seeking prenatal care services. Such situations promoted women use of home based care. ${ }^{14}$ 
Women who reported to have low utilization of maternal health care services perceived the entire maternal health care service, particularly at the postpartum care level as curative rather than preventive, a factor that contributed to low postnatal care utilization. In the southern part of Malawi, there prevailed a sense of apathy among women in as far as health seeking behavior is concerned as a result of low understanding of the significance of utilizing maternal health care services..$^{21}$ It was also noted that women's apathy toward utilization of maternal health care services is a result of poor quality of health care service delivery in addition to inadequate knowledge in as far as significance of maternal health care service utilization is concerned. ${ }^{22}$ This translated into delayed or no drive to use maternal health care services in general. It is therefore not surprising that the level of utilization of maternal health care services among women before and after childbirth is not congruent due to inadequate knowledge of the significance of seeking institutional-based health service delivery with regard to maternal health among women. Such influences have seen women in Uganda having challenges in delivering in modern health care facilities. ${ }^{12}$

A number of issues on maternal health care services in general have to be addressed if women are to be encouraged to use the services entirely. For instance, respondents pointed out the need for health care service stakeholders to introduce community-based ambulatory services to support women regardless of socioeconomic position. This need is far from being met, yet most African states, including Malawi, pledged that they will provide resources adequately in the health systems to ensure effective quality of health care delivery and subsequently safe motherhood. ${ }^{22,23}$

In another aspect, the quality of health care delivery is influenced by factors such as unavailability of basic standard medical resources, supplies and equipment to support delivery of maternal health care services in most health centers. This situation aggravates a human right health issue as people are not capable of accessing expected medical services, including maternal care services. This situation characterized by shortage of essential resources to meet women's health needs demotivates them from relying on the services provided by the facility. This consequently forces women to seek services from unreliable and risky home-based alternatives over institutional-based services and, as such, get exposed to risk of ill health as a result of substandard care acquired from such alternative providers. Such neglected quality of maternal health care delivery issues significantly translates into underutilization of services and consequently worsens maternal health outcome. ${ }^{24}$
Another problem is the shortage of health care resource personnel within the health care facilities. Some scholars have noted that inadequate health care resource personnel operating within the health centers in developing countries contribute positively to suboptimal services being delivered within the facilities and subsequently low quality of care. ${ }^{16,25,26}$

The congestion in maternity wards in the public health care facilities is a factor that poses as a challenge to quality care service provision in the country. In addition, there is not enough bed space to accommodate all admitted women in the hospitals, a factor that forces hospital management to try and accommodate everyone by facilitating the sharing of the few resources such as beds. This is one major barrier to women's choice of child delivery through mainstream health care facilities. Literature has shown that such developments create long-standing negative community perceptions on the quality of health care delivery in the local health care facility. Low utilization of health care facility services is also affected by the fact that most women do not have the capacity to provide their own resources while being admitted for pregnancy-related issues. Subsequently, failure of the health facility to provide maternal care material discourages them. ${ }^{27,28}$ The present study confirmed previous findings made by earlier works that it appears that health care quality issues are common across the northern, central and southern regions of Malawi. Consequently, women delay in seeking maternal health services or seek alternative help in either traditional-based or home-based childbirth delivery services, a situation that aggravates low utilization prevalence of mainstream maternal health care services.

Regarding attitude of the health care personnel during service delivery, the study found differentials in the health workers regarding their service support during prenatal, intranatal and postnatal care. Such attitudes include failure of the health workers to render personal support on women calling for specific attention while admitted in the hospital. Another study associated the health workers' attitude with negative influence on women's use of mainstream maternal health care services. In most cases, doctors and nurses were reported to be denying women care or treatment for specific maternal health needs, ${ }^{14,29}$ whereas in other instances, women were forced to clean themselves immediately after delivery, ${ }^{30,31}$ denied use of either the toilet facilities ${ }^{32}$ and/or denied access to pain killers while in the hospital after abortion. ${ }^{33}$ Such unethical and inhumane attitude of the health workers, which is often times scantly cautioned, is cited as a major 
catalyst influencing women to develop negative attitude toward mainstream maternal health care.

Regarding the family support, majority of the women indicated that their husbands were not ready and willing to support them at the time they needed maternal health care services. In an earlier study, it was found out that women and male peers are pivotal in promoting male involvement and support of their spouses during childbirth. ${ }^{34,35}$ A study $^{34}$ conducted in selected health care facilities in Malawi reported that the couple advocacy strategy, which aims at promoting men involvement on maternal health care issues, proved to be a success in Malawi despite the fact that such information was obtained from the health care providers other than the patients and their spouses or partners. In the current study, it was found that some of the participants' husbands stated that any maternal health challenges their spouse might experience are women matter and must be solved among women. Therefore, such inadequate male support experienced by women in the country remains the major barrier affecting women's use of maternal health care services in the country.

\section{Conclusion}

This study indicates that the majority of the women are satisfied with the quality of services that they receive from the health care facilities during prenatal care service visits. More importantly, those who were escorted by their spouses/partners reported that the quality of care delivery was time efficient and effective compared to their counterparts who did not come alone or were escorted by a female relative. However, most of the women were dissatisfied with the quality of services during intrapartum and postpartum periods. For instance, women were being yelled by the health care personnel and were not treated as expected. This development is contrary toward human decency who aspires to receive requisite health care, more especially from such main stream health care facilities. The study also found that women do delay to timely access and use maternal health services after conception of the pregnancy. This is partly due to cultural beliefs or fear of being bewitched, and partly to poor quality service delivery during childbirth. These situations promote women to seek maternal health care services elsewhere. This practice demotivates the health personnel to render better or selective quality of services among the women defaulters if alternative services fail and seek main stream health services. As such, it implies that numerous challenges exist from both those demanding for maternal services and from the service providers' perspectives.
Therefore, to improve utilization on the quality of maternal health care, there is need to promote and initiate spouse/partners' involvement if efficiency and effective quality of care are to be rendered and scaled up in most maternal health care facilities in Malawi. On the same note, it is also noted that most women are not treated with all decency at the time they are within the main stream health facilities seeking quality of care. This development promotes use of risky noninstitutional health care elsewhere. As such, the need to implement service quality audit checks periodically as a way of monitoring standard operating procedures and promoting maternal services delivery in general cannot be overstated. Lastly, there is need to foster community-based reproductive health education advocacy to promote male involvement in maternal health care services and understanding among women against cultural beliefs that re-fresher courses among the health workers on subjects aimed at promoting all aspects of service delivery and maternal clientele management. This will have a long-run positive perspective on the quality of maternal health care delivery and will subsequently promote use of the services.

\section{Acknowledgments}

KM was partially funded by Lilongwe University of Agriculture and Natural Resources on some logistics during data collection across Malawi. Many thanks to the university for rendering the support that enabled this work to be completed at the time.

\section{Disclosure}

The authors report no conflicts of interest in this work.

\section{References}

1. World Health Organization. Macroeconomics and Health: Investing in Health for Economic Development. Report of the Commission on Macroeconomics and Health. Geneva: World Health Organization; 2001.

2. World Health Organisation. Antenatal Care Randomized Trial: Manual for Implementation of the New Model. Geneva: World Health Organization; 2002.

3. World Health Organisation. Trends in Maternal Mortality: 1990 to 2015. Estimates by WHO, UNICEF, UNFPA, the World Bank and the United Nations Population Division. Geneva: World Health Organisation; 2015.

4. United Nations. Strengthening the Demographic Evidence Base for Post 2015 Development Agenda. New York: Department of Economic and Social Affairs; 2016.

5. Government of Malawi. Health Sector Strategic Plan. 2011-2016. Ministry of Health, Capital Hill Lilongwe, Malawi; 2012.

6. Reserve Bank of Malawi. Financial and Economic Review. Quarterly. 2015;48:2.

7. Muula AS. Nationality and country of training of medical doctors in Malawi. Afr Health Sci. 2006;6(2):118-119.

8. Government of Malawi. Malawi Road Map for Accelerating the Reduction of Maternal and Neonatal Mortality and Morbidity. Revised Version. Ministry of Health, Capital Hill Lilongwe, Malawi; 2007. 
9. NSO \& ICF Macro. Malawi Demographic and Health Survey 2010. Zomba, Malawi; Calverton, MD: NSO and ICF Macro; 2011.

10. Palamuleni M. Determinants of non-institutional deliveries in Malawi. Malawi Med J. 2011;23(4):104-108.

11. Kwambai T, Dellicour S, Desai M, et al. Perspectives of men on antenatal and delivery care service utilisation in rural western Kenya: a qualitative study. BMC Pregnancy Childbirth. 2013;13:134.

12. Kabakyenga JK, Östergren PO, Turyakira E, Pettersson KO. Influence of birth preparedness, decision-making on location of birth and assistance by skilled birth attendants among women in south-western Uganda. PLoS One. 2012;7(4):e35747.

13. Griffiths P, Stephenson R. Understanding users' perspectives of barriers to maternal health care use in Maharashtra, India. J Biosoc Sci. 2001;33(3):339-359.

14. Mrisho M, Schellenberg J, Mushi A, et al. Factors affecting home delivery in rural Tanzania. Trop Med Int Health. 2007;12(7):862-872.

15. Mathole T, Lindmark G, Majoko F, Ahlberg BM. A qualitative study of women's perspectives of antenatal care in a rural area of Zimbabwe. Midwifery. 2004;20(2):122-132.

16. Rowe AK, de Savigny D, Lanata CF, Victora CG. How can we achieve and maintain high-quality performance of health workers in lowresource settings? Lancet. 2005;366(9490):1026-1035.

17. Gouws E, Bryce J, Pariyo G, Armstrong Schellenberg J, Amaral J, Habicht JP. Measuring the quality of child health care at first-level facilities. Soc Sci Med. 2005;61(3):613-625.

18. Kutzin J. Descriptive framework for country-level analysis of health care financing arrangements. Health Policy. 2001;56(3):171-204.

19. Andaleeb S. Service quality perceptions and patient satisfaction: a study of hospitals in a developing country. Soc Sci Med. 2001;52(9): 1359-1370.

20. Christopher S, Watts V, McCormick A, Young S. Building and maintaining trust in a community-based participatory research partnership. Am J Public Health. 2008;98(8):1398-1406.

21. Sakala B, Kazembe A. Factors influencing the utilisation of postnatal care at one week and six weeks among mothers at Zomba Central Hospital in Malawi. Evid Based Midwifery. 2011;9:131.

22. World Health Organization. Abuja Declaration. Ten Years on. Geneva: World Health Organization; 2011.
23. Safe Motherhood Initiatives. Facts and Figures. Geneva: World Health Organization; 2006.

24. Graham W, McCaw-Binns A, Munjanja S. Translating coverage gains into health: the neglected agenda. Int J Gynecol Obstet. 2013;116: $118-121$.

25. Koblinsky M, Matthews Z, Hussein J, et al. Lancet maternal survival series steering group. Going to scale with professional skilled care. Lancet. 2006;368:1377-1378.

26. Franco LM, Bennett S, Kanfer R, Stubblebine P. Determinants and consequences of health worker motivation in hospitals in Jordan and Georgia. Soc Sci Med. 2004;58(2):343-355.

27. Kruk M, Kujawski S, Mbaruku G, et al. Disrespectful and abusive treatment during facility delivery in Tanzania: a facility and community survey. Health Policy Plan. 2014;1-8:czu079.

28. Thaddeus S, Maine D. Too far to walk: maternal mortality in context. Soc Sci Med. 1994;38(8):1091-1110.

29. Chapman R. Endangering safe motherhood in Mozambique: prenatal care as pregnancy risk. Soc Sci Med. 2003;57(2):355-374.

30. Miller S, Cordero M, Coleman A, et al. Quality of care in institutionalized deliveries: the paradox of the Dominican Republic. Int J Gynaecol Obstet. 2003;82(1):89-103.

31. Jaffré Y, Prual A. Midwives in Niger: an uncomfortable position between social behaviours and health care constraints. Soc Sci Med. 1994;38(8):1069-1073.

32. Gao Y, Barclay L, Kildea S, Hao M, Belton S. Barriers to increasing hospital birth rates in rural Shanxi Province, China. Reprod Health Matters. 2010;18(36):35-45.

33. Solo J. Easing the pain: pain management in the treatment of incomplete abortion. Reprod Health Matters. 2010;8(15):45-51.

34. Kululanga LI, Sundby J, Malata A, Chirwa E. Striving to promote male involvement in maternal health care in rural and urban settings in Malawi - a qualitative study. Reprod Health. 2011;8:36.

35. Mullany B, Becket S, Hindin M. The impact of including husbands in antenatal health education services on maternal health practices in urban Nepal: results from a randomised controlled trial. Health Educ Res. 2007;22(2):166-176.
International Journal of Women's Health

\section{Publish your work in this journal}

The International Journal of Women's Health is an international, peerreviewed open-access journal publishing original research, reports, editorials, reviews and commentaries on all aspects of women's healthcare including gynecology, obstetrics, and breast cancer. The manuscript management system is completely online and includes

\section{Dovepress}

a very quick and fair peer-review system, which is all easy to use Visit http://www.dovepress.com/testimonials.php to read real quotes from published authors. 